\title{
Optical Control of Glycerolipids and Sphingolipids
}

\author{
Dirk Trauner ${ }^{\star a}$ and Johannes Morstein ${ }^{\star b}$
}

\begin{abstract}
Glycerolipids, sphingolipids, and sterols are the three major classes of membrane lipids. Both glycerolipids and sphingolipids are comprised of combinations of polar headgroups and fatty acid tails. The fatty acid tail can be chemically modified with an azobenzene photoswitch giving rise to photoswitchable lipids. This approach has yielded a number of photopharmacological tools that allow for the control various of aspects of lipid assembly, metabolism, and physiology with light.
\end{abstract}

Keywords: Glycerolipids · Photopharmacology $\cdot$ Photoswitches · Sphingolipids

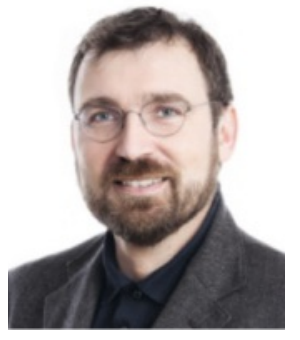

Dirk Trauner studied biology and biochemistry at the University of Vienna, Austria, before he joined Prof. Dr. Johann Mulzer's group at the FU Berlin, Germany, to pursue natural product synthesis. Subsequently, he was a postdoctoral fellow with Prof. Dr. Samuel J. Danishefsky at the Memorial Sloan-Kettering Cancer Center. In 2000, he joined the University of California, Berkeley, USA, where he rose through the ranks to become an Associate Professor of chemistry (with tenure). In 2008, he moved to the University of Munich, Germany, as a Professor of Chemistry and Chemical Biology. In March 2017, he was appointed the Janice Cutler Chair in Chemistry at NYU, where he also resides as adjunct Professor of Neurosciences and Physiology. His research interests range from organic synthesis and natural product chemistry to chemical neurobiology, optogenetics, and photopharmacology.

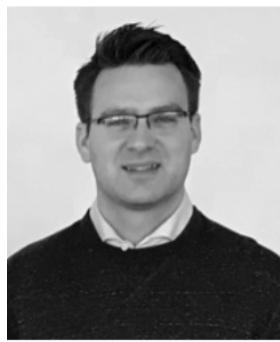

Johannes Morstein received his B.S. and M.S. in Chemistry and Biochemistry from LMU Munich. During his Master's, he worked with Prof. Dr. Christopher J. Chang on the development of small-molecule fluorescent sensors and Prof. Dr. John F. Hartwig on the functionalization of $\mathrm{C}-\mathrm{Si}$ bonds at UC Berkeley. As a PhD student in the Trauner laboratory, he worked on the development of photoswitchable glycerolipids and sphingolipids. He is currently a NIH NCI K00 postdoctoral fellow in the laboratory of Prof. Dr. Kevan Shokat at UCSF.

\section{Introduction}

Glycerolipids and sphingolipids both exhibit acyl chains as hydrophobic tails. ${ }^{[1,2]}$ These can be chemically modified to afford functionalized lipids, such as isotopically labeled lipids, fluorescent lipids, and photocrosslinking lipids, which have empowered the field of lipid research. ${ }^{[3,4]}$ Such lipids enable the quantifica-

*Correspondence: Prof. D. Traunera E-mail: dirktrauner@nyu.edu,

aDept. Chemistry, NYU, NYC, NY 10003;

Dr. J. Morstein ${ }^{\mathrm{b}}$, E-Mail: johannes.morstein@ucsf.edu,

${ }^{b}$ Dept. Cell. And Mol. Pharmacoloy, UCSF, SF, CA 94158 tion, visualization, and interaction profiling of lipids in biological systems. The ability for precise control of lipid function would add a highly attractive functional modification to this toolset. An important approach towards the optical control of lipid function is the installation of photocleavable protecting groups on lipid headgroups. However, while chemical methods continue to evolve, this strategy requires unique chemical strategies for different lipid headgroups and is therefore not as modular as lipid tail functionalizations. Photocaged lipids are reviewed elsewhere and not covered in this account. ${ }^{[5,6]}$

We have recently started to systematically explore a new approach for the optical control of lipids that relies on the incorporation of hydrophobic molecular photoswitches in the fatty acid tails of lipids. ${ }^{[7,8]}$ In this review, we describe applications to the classes of glycerolipids and sphingolipids. A large number of natural and synthetic amphiphiles has also been successfully addressed with this approach but these applications go beyond the scope of this review. They include lipopeptides ${ }^{[9]}$ and natural and synthetic bioactive amphiphiles that do not belong to the classes of glycerolipids or sphingolipids, such as nuclear hormone receptor ligands ${ }^{[10-12]}$ or cannabinoids. ${ }^{[13,14]}$

\section{Optical Control of Glycerolipids}

Glycerolipids consist of a glycerol backbone coupled to 1-3 fatty acids. In many cases one hydroxyl group is conjugated to a phosphate-containing headgroup giving rise to glycerophospholipids.

\subsection{Lysophosphatidic Acid (LPA) ${ }^{[15]}$}

Lysophosphatidic acid (LPA) is a potent signaling lipid that activates a family of $\mathrm{G}$ protein-coupled receptors (LPA receptors 1-6) with low nanomolar $K_{D}$ values. ${ }^{[16,17]}$ A photoswitchable analog of LPA, termed AzoLPA (Fig. 1C), was developed through incorporation of an azobenzene with the $\mathrm{N}=\mathrm{N}$ double bond near the middle of the lipid tail. This corresponded to the position of the cis- $\mathrm{C}=\mathrm{C}$ double bond in the predominant form of LPA $(18: 1)$ and yielded a photolipid that activates LPA receptors with higher potency in its light-induced cis-form (Fig. 2A). The usefulness of this tool for the optical control of LPA physiology was demonstrated through the activation of neurite retraction.

\subsection{Phosphatidic Acid (PA). ${ }^{[18]}$}

Phosphatidic acids (PAs) are signaling lipids that regulate two major cell growth pathways, mTOR and Hippo signaling. Photoswitchable analogues of PA, that contain azobenzenes in one or both lipid tails, respectively, were developed. The analog with two azobenzenes, termed dAzoPA, enabled the control of 
both signaling pathways. mTOR signaling was activated and Hippo signaling was inhibited by the light-activated cis-form, both contributing to cellular proliferation (Fig. 2C).

\subsection{Diacylglycerol (DAG) ${ }^{[19,20]}$}

Diacylglycerol (DAG) is a second messenger lipid, which translocates $\mathrm{C} 1$-domain containing proteins to the plasma membrane leading to their activation. Photoswitchable analogs, termed PhoDAGs, enabled optical control of protein kinase $\mathrm{C}$ and Munc13. Derivatives with two azobenzene-containing lipid tails, termed OptoDArG, were found to exhibit larger effects on the transient receptor potential channel TRPC3.

\subsection{Phosphatidylcholine (PC) ${ }^{[21,22]}$}

Photoswitchable derivatives of phosphatidylcholine date back much further than the other photolipids described in this review. They were extensively used to control various aspects of lipid assembly, such as supramolecular aggregation, liposome fusion,
A

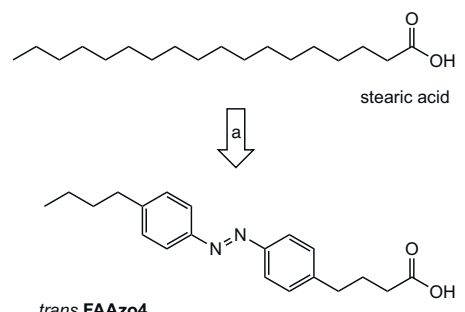

$\begin{gathered}365 \mathrm{~nm} \\ \text { PSS }=1: 9\end{gathered} \| \begin{gathered}460 \mathrm{~nm} \\ P S S=9: 1 \\ \tau=2 \mathrm{~d}\end{gathered}$

cis FAAzo4<smiles>CCCCc1ccc(N=Nc2ccc(CCCC(=O)O)cc2)cc1</smiles>

B

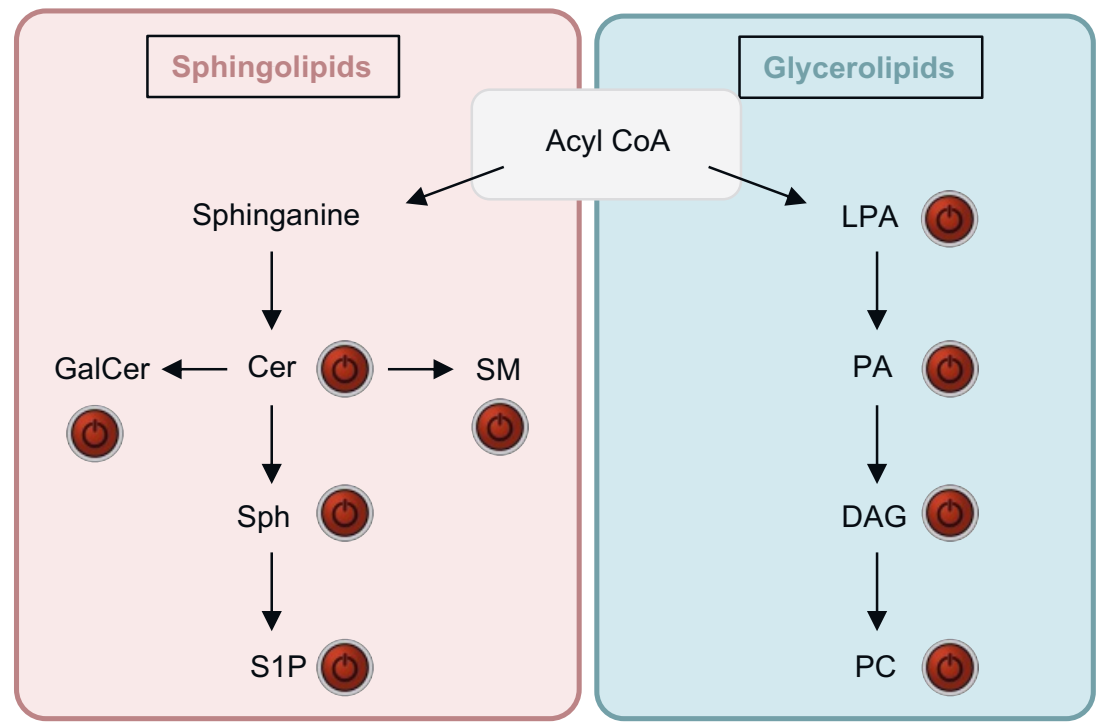

C
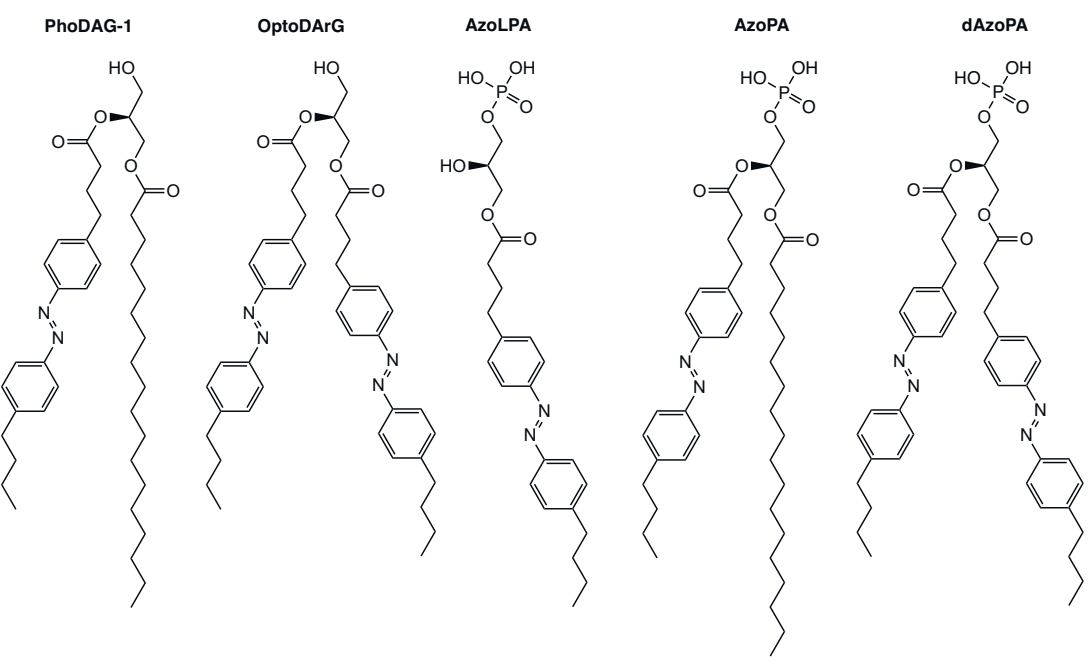

D Photosph
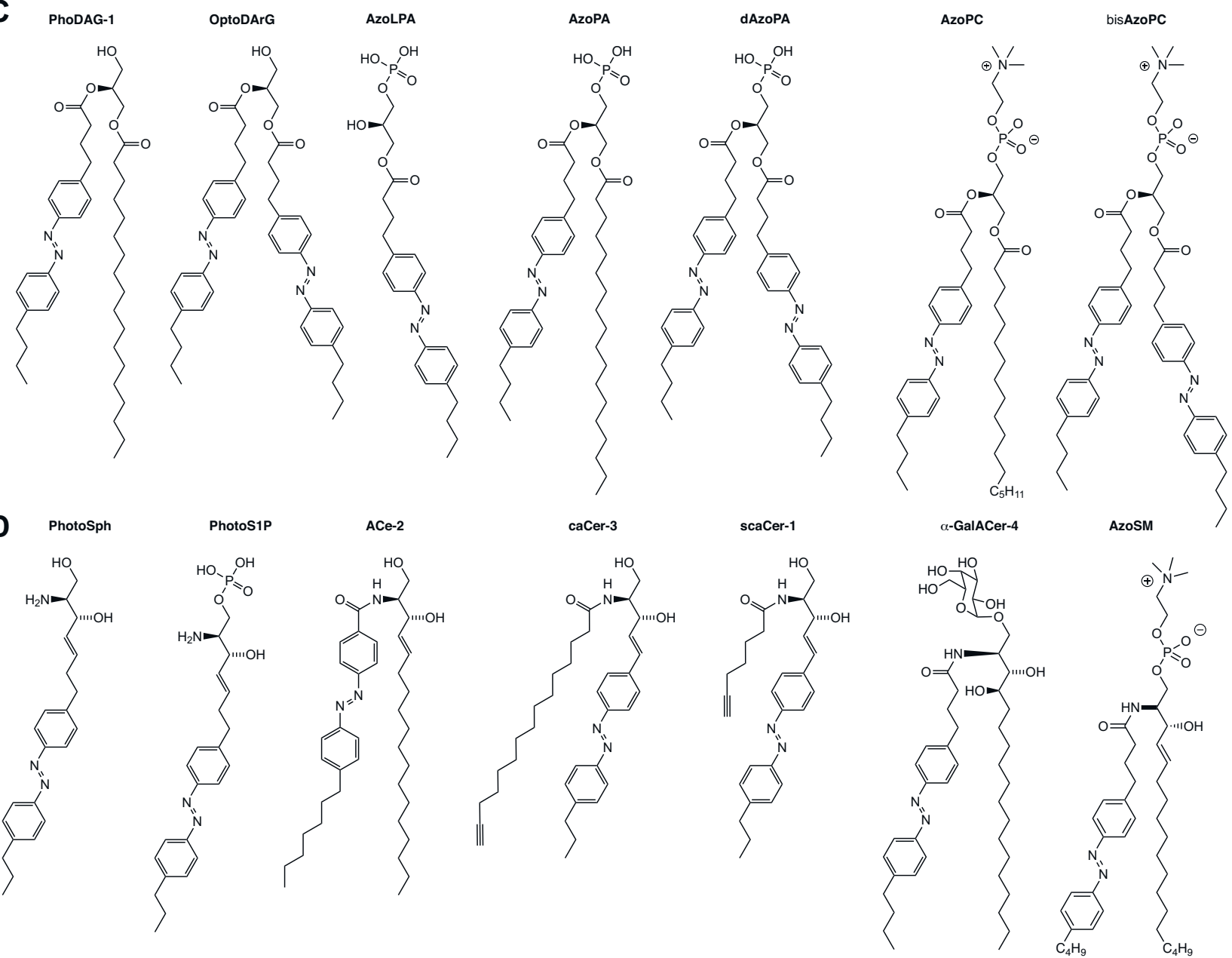

Fig. 1. Overview of photoswitchable glycerolipids and sphingolipids. (A) Photoisomerization of the photoswitchable lipid FAAZo4. (B) Metabolic pathways of sphingolipids and glycerolipids. (C) Photoswitchable glycerolipids developed to date. (D) Photoswitchable sphingolipids developed to date. 

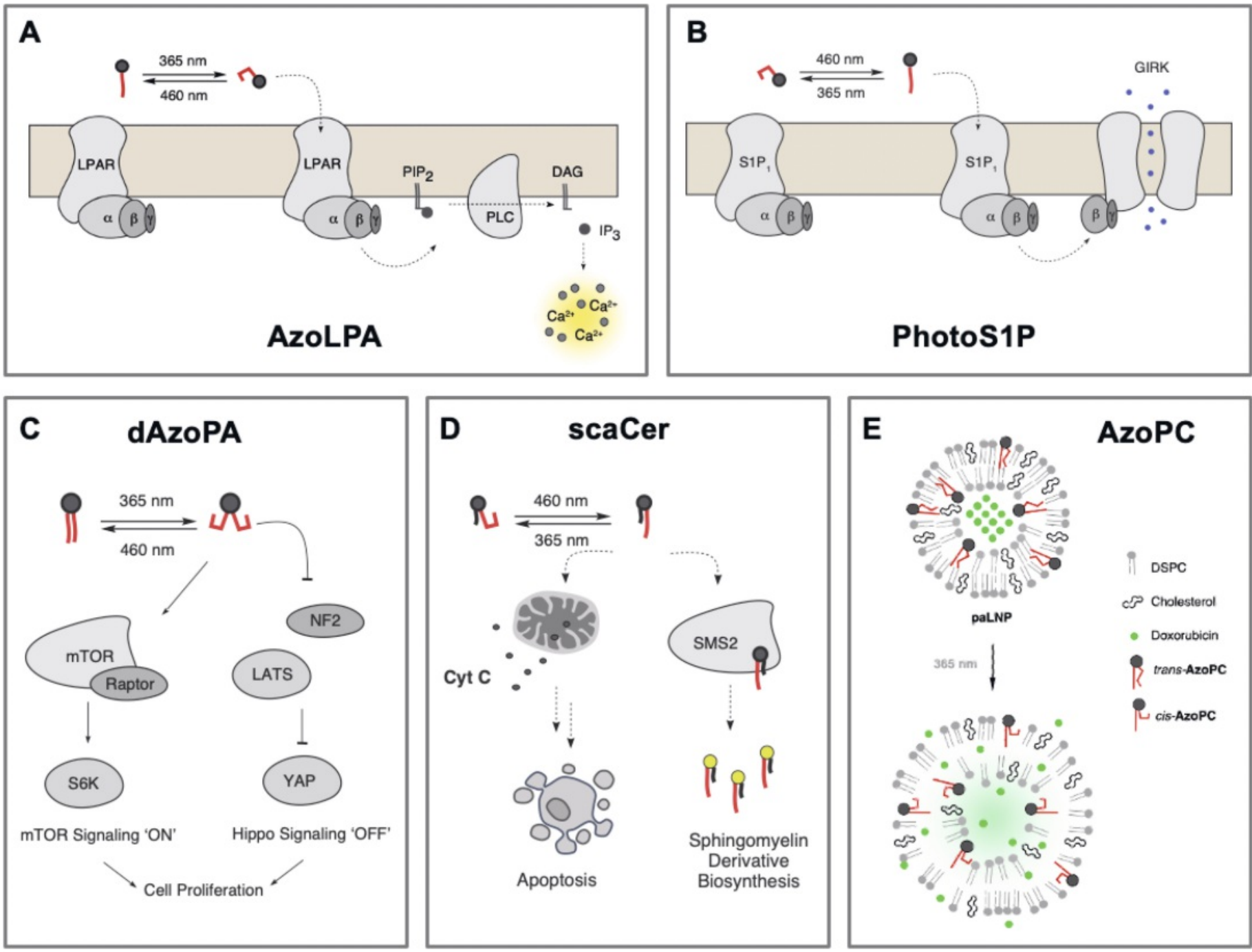

Fig. 2. Schemes that exemplify applications of photoswitchable lipids. (A) Optical control of $\mathrm{G}_{\mathrm{q}}$-coupled LPA receptors with AzoLPA. (B) Optical control of S1P receptor 1 coupled to GIRK with PhotoS1P. (C) Optical control of mTOR and Hippo Signaling with dAzoPA. (D) Optical control of apoptosis and sphingolipid metabolism with scaCer, (E) Optical control of doxorubicin release from paLNPs containing AzoPC.

or lipid exchange. ${ }^{[21-23]}$ Recent applications by the Lohmüller and Trauner groups include reversible control of lipid organization and fluidity. ${ }^{[24,25]}$ Additionally, AzoPC has recently been used to study protein-membrane interactions with NMR spectroscopy ${ }^{[26]}$ and to control the release of cargo from liposomes in cells and in vivo (Fig. 2E). ${ }^{[27]}$

\section{Optical Control of Sphingolipids}

Sphingolipids consist of a sphingoid base backbone that is commonly modified with an N-acyl chain. Similarly to glycerolipids, the primary alcohol can also be functionalized with a phosphate-containing headgroup. ${ }^{[2,28]}$

\subsection{Ceramides [Cer] ${ }^{[29-31]}$}

Ceramides form a central node of sphingolipid metabolism and can be converted into various other bioactive lipids, including sphingomyelin, ceramide-1-phosphate, acylceramides, glyco-sphingolipids, and sphingosine. ${ }^{[32]}$ In addition, they can undergo lipid phase separation and also fulfill important signaling functions, including induction of apoptosis. Photoswitchable analogs of ceramides were first used to control lipid phase separation in supported lipid bilayers. ${ }^{[29]}$ Bifunctional clickable and azobenzene-containing analogs are photoswitchable substrates for both sphingomyelin synthase and glucosylceramide syn- thase, enabling optical control of sphingolipid metabolism. ${ }^{[30]}$ Finally, short chain analogs were developed to control aspects of ceramide signaling in cells (Fig. 2D). They were shown to enable optical control of apoptosis. ${ }^{[31]}$

\subsection{Sphingosine [Sph] and Sphingosine-1-Phosphate [S1P][33]}

Sphingosine and Sphingosine-1-Phosphate (S1P) are signaling lipids. ${ }^{[28]}$ Similarly to LPA, S1P activates a family of G protein-coupled receptors, the S1P receptors $1-5$, which are implicated in various physiological processes. ${ }^{[34]}$ A photoswitchable analog of sphingosine, termed PhotoSph, was a photoswitchable substrate of sphingosine kinase 1 and 2. The corresponding S1P probe, PhotoS1P, enabled optical control of the S1P receptors as demonstrated with various methods and applications (Fig. 2B). These included the optical control of thermal hypersensitivity in vivo via a S1PR3/TRPV1 signaling axis without genetic intervention. ${ }^{[33]}$

\subsection{Sphingomyelin [SM] ${ }^{[35]}$}

Sphingomyelin is the most abundant sphingolipid. ${ }^{[28]}$ Like ceramide, sphingomyelin can undergo membrane phase separation. A photoswitchable analog of SM, termed AzoSM, enabled optical control of domain formation in supported lipid bilayers. ${ }^{[35]}$ 


\subsection{GalCers ${ }^{[36,37]}$}

$\alpha$-Galactosylceramides activate natural killer T cells, resulting in cytokine production. Photoswitchable analogs of this immunomodulatory lipid enabled optical control of production of the cytokines IFN- $\gamma$ and IL-4. ${ }^{[36,37]}$

\section{Conclusions}

The number of glycero- and sphingolipids that been successfully converted into photolipids to date suggests that this approach is broadly applicable to these classes of lipids. Lipid MAPS currently contains nearly 5000 unique sphingolipids and almost 8000 unique glycerolipids. Based on the success rate, we believe that our approach could be amenable to the majority of these lipids, offering numerous opportunities for the spatiotemporal control of their function. Different positioning of the azobenzene switch further allows researchers to address the diversity found in lipid tail structures.

\section{Acknowledgements}

J. M. thanks the NCI for a K00 award (4K00CA253758). We thank Dr. Tufan Mukhopadhyay for proofreading the manuscript.

\section{Received: October 27, 2021}

[1] G. van Meer, D. R. Voelker, G. W. Feigenson, Nat. Rev. Mol. Cell Biol. 2008 9, 112, https://doi.org/10.1038/nrm2330.

[2] T. Harayama, H. Riezman, Nat. Rev. Mol. Cell Biol. 2018, 19, 281, https://doi.org/10.1038/nrm.2017.138.

[3] T. W. Bumpus, J. M. Baskin, Trends Biochem. Sci. 2018, 43, 970, https://doi.org/10.1016/j.tibs.2018.09.011.

[4] J. Flores, B. M. White, R. J. Brea, J. M. Baskin, N. K. Devaraj, Chem. Soc. Rev. 2020, 49, 4602, https://doi.org/10.1039/D0CS00154F.

[5] D. Höglinger, A. Nadler, C. Schultz, Biochim. Biophys. Acta (BBA) - Mol. Cell Biol. Lipids 2014, 1841, 1085, https://doi.org/10.1016/j.bbalip.2014.03.012.

[6] S. Farley, A. Laguerre, C. Schultz, Curr. Opin. Chem. Biol. 2021, 65, 42, https://doi.org/10.1016/j.cbpa.2021.04.012.

[7] K. Hüll, J. Morstein, D. Trauner, Chem. Rev. 2018, 118, 10710, https://doi.org/10.1021/acs.chemrev.8b00037

[8] J. Morstein, A. C. Impastato, D. Trauner, ChemBioChem 2021, 22, 73, https://doi.org/10.1002/cbic.202000449.

[9] H.-G. Hu, P.-G. Chen, G. Wang, J.-J. Wu, B.-D. Zhang, W.H. Li, R. L. Davis, Y.-M. Li, ChemBioChem 2019, 21, 1150, https://doi.org/10.1002/cbic.201900591.

[10] J. Morstein, M. Awale, J.-L. Reymond, D. Trauner, ACS Cent. Sci. 2019, 5 , 607, https://doi.org/10.1021/acscentsci.8b00881

[11] J. Morstein, J. B. Trads, K. Hinnah, S. Willems, D. M. Barber, M. Trauner, D. Merk, D. Trauner, Chem. Sci. 2020, 11, 429, https://doi.org/10.1039/C9SC02911G.

[12] K. Hinnah, S. Willems, J. Morstein, J. Heering, F. W. W. Hartrampf, J. Broichhagen, P. Leippe, D. Merk, D. Trauner, J. Med. Chem. 2020, 63, 10908, https://doi.org/10.1021/acs.jmedchem.0c00654.

[13] M. V. Westphal, M. A. Schafroth, R. C. Sarott, M. A. Imhof, C. P. Bold, P. Leippe, A. Dhopeshwarkar, J. M. Grandner, V. Katritch, K. Mackie, D. Trauner, E. M. Carreira, J. A. Frank, J. Am. Chem. Soc. 2017, 139, 18206, https://doi.org/10.1021/jacs.7b06456.

[14] R. C. Sarott, A. E. G. Viray, P. Pfaff, A. Sadybekov, G. Rajic, V. Katritch, E. M. Carreira, J. A. Frank, J. Am. Chem. Soc. 2021, 143, 736, https://doi.org/10.1021/jacs.0c08926.

[15] J. Morstein, M. A. Dacheux, D. D. Norman, A. Shemet, P. C. Donthamsetti, M. Citir, J. A. Frank, C. Schultz, E. Y. Isacoff, A. L. Parrill, G. J. Tigyi, D. Trauner, J. Am. Chem. Soc. 2020, 142, 10612, https://doi.org/10.1021/jacs.0c02154.

[16] I. Ishii, N. Fukushima, X. Ye, J. Chun, Ann. Rev. Biochem. 2004, 73, 321, https://doi.org/10.1146/annurev.biochem.73.011303.073731.

[17] Y. C. Yung, N. C. Stoddard, J. Chun, J. Lipid Res. 2014, 55, 1192 https://doi.org/10.1194/jlr.R046458.
[18] R. Tei, J. Morstein, A. Shemet, D. Trauner, J. M. Baskin, ACS Cent. Sci. 2021, 7, 1205, https://doi.org/10.1021/acscentsci.1c00444.

[19] J. A. Frank, D. A. Yushchenko, D. J. Hodson, N. Lipstein, J. Nagpal, G. A Rutter, J.-S. Rhee, A. Gottschalk, N. Brose, C. Schultz, D. Trauner, Nat. Chem. Biol. 2016, 12, 755, https://doi.org/10.1038/nchembio.2141.

[20] M. Lichtenegger, O. Tiapko, B. Svobodova, T. Stockner, T. N. Glasnov, W. Schreibmayer, D. Platzer, G. G. de la Cruz, S. Krenn, R. Schober, N. Shrestha, R. Schindl, C. Romanin, K. Groschner, Nat. Chem. Biol. 2018, 14 396, https://doi.org/10.1038/s41589-018-0015-6.

[21] X. Song, J. Perlstein, D. G. Whitten, J. Am. Chem. Soc. 1997, 119, 9144, https://doi.org/10.1021/ja972292i.

[22] C. G. Morgan, Y. P. Yianni, S. S. Sandhu, A. C. Mitchell, Photochem. Photobiol. 1995, 62, 24 , https://doi.org/10.1111/j.1751-1097.1995.tb05233.x.

[23] C. Pernpeintner, J. A. Frank, P. Urban, C. R. Roeske, S. D. Pritzl, D. Trauner, T. Lohmüller, Langmuir 2017, 33, 4083, https://doi.org/10.1021/acs.langmuir.7b01020.

[24] P. Urban, S. D. Pritzl, D. B. Konrad, J. A. Frank, C. Pernpeintner, C. R. Roeske, D. Trauner, T. Lohmüller, Langmuir 2018, 34, 13368 https://doi.org/10.1021/acs.langmuir.8b03241.

[25] P. Urban, S. D. Pritzl, M. F. Ober, C. F. Dirscherl, C. Pernpeintner, D. B Konrad, J. A. Frank, D. Trauner, B. Nickel, T. Lohmueller, Langmuir 2020 36, 2629, https://doi.org/10.1021/acs.langmuir.9b02942.

[26] M. Doroudgar, J. Morstein, J. Becker-Baldus, D. Trauner, C. Glaubitz, J. Am. Chem. Soc. 2021, 143, 9515, https://doi.org/10.1021/jacs.1c03524.

[27] N. Chander, J. Morstein, J. S. Bolten, A. Shemet, P. R. Cullis, D. Trauner, D. Witzigmann, Small 2021, 17, 2008198, https://doi.org/10.1002/smll.202008198.

[28] Y. A. Hannun, L. M. Obeid, Nat. Rev. Mol. Cell Biol. 2008, 9, 139, https://doi.org/10.1038/nrm2329.

[29] J. A. Frank, H. G. Franquelim, P. Schwille, D. Trauner, J. Am. Chem. Soc 2016, 138, 12981, https://doi.org/10.1021/jacs.6b07278.

30] M. Kol, B. Williams, H. Toombs-Ruane, H. G. Franquelim, S. Korneev, C. Schroeer, P. Schwille, D. Trauner, J. C. Holthuis, J. A. Frank, eLife 2019, 8 , e43230, https://doi.org/10.7554/eLife.43230.

[31] J. Morstein, M. Kol, A. J. E. Novak, S. Feng, S. Khayyo, K. Hinnah, N. Li-Purcell, G. Pan, B. M. Williams, H. Riezman, G. E. AtillaGokcumen, J. C. M. Holthuis, D. Trauner, ACS Chem. Biol. 2021, 16, 452, https://doi.org/10.1021/acschembio.0c00823.

[32] Y. A. Hannun, L. M. Obeid, Nat. Rev. Mol. Cell Biol. 2018, 19, 175, https://doi.org/10.1038/nrm.2017.107.

[33] J. Morstein, R. Z. Hill, A. J. E. Novak, S. Feng, D. D. Norman, P. C. Donthamsetti, J. A. Frank, T. Harayama, B. M. Williams, A. L. Parrill, G. J. Tigyi, H. Riezman, E. Y. Isacoff, D. M. Bautista, D. Trauner, Nat. Chem. Biol. 2019, 15, 623, https://doi.org/10.1038/s41589-019-0269-7.

[34] G. T. Kunkel, M. Maceyka, S. Milstien, S. Spiegel, Nat. Rev. Drug Discov. 2013, 12, 688, https://doi.org/10.1038/nrd4099.

[35] N. Hartrampf, S. M. Leitao, N. Winter, H. Toombs-Ruane, J. A Frank, P. Schwille, D. Trauner, H. G. Franquelim, bioRxiv 2021, https://doi.org/10.1101/2021.10.11.463883.

[36] N. Hartrampf, T. Seki, A. Baumann, P. Watson, N. A. Vepřek, B. E. Hetzler, A. Hoffmann-Röder, M. Tsuji, D. Trauner, Chem. Eur. J. 2020, 26, 4476, https://doi.org/10.1002/chem.201905279.

[37] T. Kanamori, T. Numata, S. Kuwabara, Y. Ishii, H. Watarai, H. Yuasa, Bioorg. Med. Chem. Lett. 2020, 30, 126960 , https://doi.org/10.1016/j.bmcl.2020.126960.

\section{License and Terms}

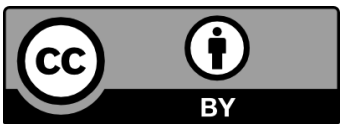

This is an Open Access article under the terms of the Creative Commons Attribution License CC BY 4.0. The material may not be used for commercial purposes.

The license is subject to the CHIMIA terms and conditions: (http:// chimia.ch/component/sppagebuilder/?view=page $\& i d=12$ ).

The definitive version of this article is the electronic one that can be found at https://doi.org/10.2533/chimia.2021.1022 